\title{
ANÁLISE SUSCINTA SOBRE A TENTATIVA NO FURTO PRIVILEGIADO
}

Raquel do Prado Paula, Márcia Lucchino Ferreira, Luciana Claudia Silva Lima, Fabio Ferreira Morong

Universidade do Oeste Paulista - UNOESTE, Presidente Prudente, SP. Curso de Direito E-mail: pradopaula@hotmail.com

\section{RESUMO}

O presente trabalho tem por objetivo realizar um estudo acerca do cabimento da tentativa no delito de furto privilegiado previsto no $\S 2$ 2 do artigo 155 do código penal. O método aplicado foi o dedutivo legal, baseado na interpretação de jurisprudências, Constituição, legislação, teorias, e doutrinas semelhantes. Conclui-se que, de fato não existem escritos detalhados sobre a possibilidade, porém a jurisprudência tem reconhecido à tentativa nos crimes de furto privilegiado, o que embasa o estudo à luz de um prisma jurisprudencial.

Palavras - chave: Furto. Furto privilegiado. Tentativa. Cabimento.

\section{SUCCINCT ANALYSIS ABOUT ATTEMPTED PRIVILEGED THEFT}

\section{ABSTRACT}

The present work have for objective, realize a study about the attempted in the crime of privileged theft, as provided in $\S 20$ in the article 155 of the penal code. The Method applied was legal deductive based in the interpretation of jurisprudence, constitution, regulation, theories and similar doctrines. It concludes that, indeed there is not detailed writer about the possibility, but the jurisprudence have recognized the attempted in the crimes of privileged theft, wich support the study the light of prism case-law.

Keywords: Theft. Primitive theft. Attempt. Fitting. 


\section{INTRODUÇÃO}

O furto privilegiado está previsto no art. 155, § 2ำ do Código Penal (BRASIL, 1940) e se trata de um furto com causa de diminuição de pena, nos seguintes termos: "se o criminoso é primário, e é de pequeno valor a coisa furtada, o juiz pode substituir a pena de reclusão pela de detenção, diminuí-la de um a dois terços, ou aplicar somente a pena de multa".

Em relação ao delito do referido artigo, que trata do furto privilegiado, será abordado no presente estudo a possibilidade do cabimento da tentativa.

De forma geral o furto privilegiado tem sido julgado com base no principio da insignificância, e subsidiariamente aplicado a causa de diminuição de pena do § 20 do artigo 155 do Código Penal (BRASIL, 1940), porém, a questão do presente estudo gira em torno da possibilidade do cabimento da tentativa no delito de furto privilegiado.

Visando uma conclusão mais concreta o presente estudo tem o objetivo de analisar, do ponto de vista doutrinário e jurisprudencial, a possibilidade do cabimento da tentativa do furto privilegiado, através de conceitos trazidos pelos juristas bem como julgamentos realizados. Majoritariamente os tribunais têm entendido e afirmado que é possível o cabimento da tentativa no furto privilegiado.

O presente trabalho tem por objetivo realizar um estudo acerca do cabimento da tentativa no delito de furto privilegiado previsto no $\S 2$ o do artigo 155 do código penal, (BRASIL, 1940). Para o desenvolvimento do presente trabalho foram utilizadas pesquisas bibliográficas e estudo de julgados envolvendo delito de tentativa de furto privilegiado.

\section{METODOLOGIA}

Para elaboração do presente trabalho utilizou-se da metodologia da pesquisa bibliográfica, utilizando materiais como doutrinas, legislação nacional e jurisprudências, que são pertinentes para o objeto em estudo. 0 método dedutivo também fora utilizado para sistematizar os dados coletados a fim de cumprir o objetivo proposto.

\section{DO FURTO}

Previsto no artigo 155 do Código Penal (BRASIL, 1940) o crime de furto consiste em subtrair coisa alheia móvel, ou seja, tomar para si aquilo que não lhe pertence, ressalta-se que a subtração ocorre sem a violência ou grave ameaça.

O elemento do tipo consiste em subtrair, tendo o sentido de retirar, tomar de alguém coisa alheia móvel.

De acordo com Rogério Grego (2016, p.536), pondera-se que:

A finalidade de ter a coisa alheia móvel para si ou para outrem é que caracteriza o chamado animus furandi no delito de furto. Não basta a subtração, o arrebatamento meramente temporário, com o objetivo de devolver a coisa alheia móvel logo em seguida. É da essência do delito de furto, portanto, que a subtração ocorra com a finalidade de ter o agente a res furtiva para si ou para outrem. Caso contrário, seu comportamento será considerado um indiferente penal, caracterizando-se aquilo que a doutrina convencionou chamar, em nossa opinião equivocadamente, de furto de uso, cuja analise será levada a efeito mais adiante.

No delito de furto verifica-se que o seu objeto consiste na coisa alheia móvel. Devese ter o cuidado para que não se confunda a coisa móvel estabelecida pelo direito civil com a 
do direito penal. Pois o direito penal entende coisa móvel como tudo aquilo que pode ser removido, ao contrário do direito civil que possui conceitos que não se aplicam ao direito penal, conforme se verifica em seu artigo 81 (BRASIL, 2002):

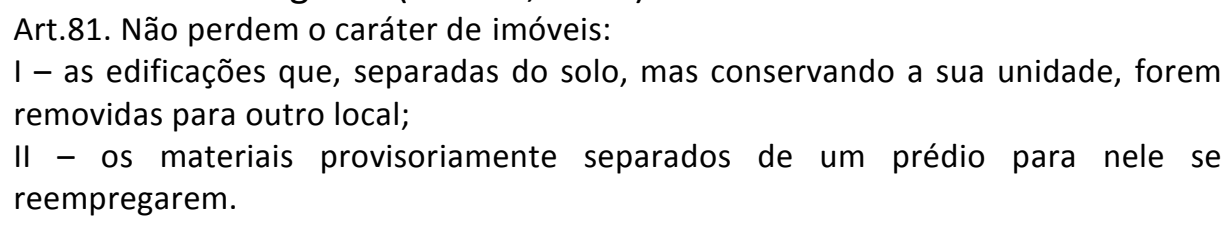

Assim, como exemplifica Rogério Greco (2016), a janela de um imóvel que foi momentaneamente retirada não perde sua natureza de imóvel, porém, para o Direito Penal, é possível a sua subtração consequentemente sua caracterização como delito de furto, pois é possível a sua remoção. A lei penal abrange os animais como coisa móvel.

Além dos elementos citados acima, o tipo penal exige também que a coisa seja alheia, ou seja, que pertença a alguém, porém, observando sempre os institutos res nullius (coisa de ninguém), a res derelicta (coisa abandonada), e a res commune omnium (coisa de uso de todos). Pois quando se tratar dos mesmos não se configura delito de furto. Em relação à res desperdicta (coisa perdida), a conduta poderá se enquadrar no artigo 169, inciso II, do Código Penal (BRASIL, 1940) que prevê o crime de apropriação de coisa achada.

Por se tratar o delito de furto de crime comum, qualquer pessoa pode ser sujeito ativo vez que a legislação não exige nenhuma característica especifica para o mesmo. É necessário fazer algumas ressalvas importantes em relação ao assunto tratado como a que o proprietário da coisa não poderá ser sujeito passivo, se o sujeito já estava na posse ou na detenção da coisa, não se enquadra no artigo 155 do código penal (BRASIL, 1940), mas sim no artigo 168 do mesmo dispositivo, que se trata da apropriação indébita. O sujeito passivo pode ser pessoa física ou jurídica que tenha a propriedade, a posse ou a detenção do bem móvel.

\section{TENTATIVA}

O iter criminis denominado caminho do crime é o conjunto de fases cronológicas para o desenvolvimento do delito. Desde quando o agente cogita até a consumação do delito existe todo um processo, ou seja, o caminho do crime. O iter criminis comporta duas fases, a interna e a externa, na primeira diz respeito a cogitação, e a segundo aos atos preparatórios, executórios e a consumação. A cogitação é a fase em que o agente mentaliza o delito bem como o resultado que deseja alcançar, após mentalizar sua ação o mesmo inicia sua preparação para obter êxito na sua pratica delituosa, por exemplo, aquisição de uma arma para pratica de homicídio, ou de uma chave falsa para prática de furto. A terceira fase do iter criminis é a execução em que o agente pode alcançar a consumação do delito, como pretendido, ou poderá não alcançar a consumação por circunstancias alheias a sua vontade.

Rogerio Grego (2016), explica uma ultima fase do iter criminis como sendo o exaurimento, que ocorre em apenas em determinadas infrações penais, e é a fase em que se situa após a consumação do delito, esgotando-o plenamente.

O presente tem por foco a não consumação do delito por circunstancias alheias a vontade do agente, qual seja, o crime tentado.

O artigo 14 do Código Penal (BRASIL, 1940) traz o seguinte conceito de tentativa:

Art. 14 - Diz-se o crime:

(...) 
Tentativa

II - tentado, quando, iniciada a execução, não se consuma por circunstâncias alheias à vontade do agente. (Incluído pela Lei no 7.209, de 11.7.1984)

Parágrafo único - Salvo disposição em contrário, pune-se a tentativa com a pena correspondente ao crime consumado, diminuída de um a dois terços. (Incluído pela Lei $n$ o 7.209, de 11.7.1984).

É também conhecida como conatus, crime imperfeito, ou crime incompleto. Quanto à sua natureza jurídica da tentativa, trata-se de uma norma de extensão ou ampliação da conduta, pois não possui autonomia dentro das definições do Código Penal. Guilherme de Souza Nucci (2017, p.172) expõe:

Tendo em vista que o legislador não criou "tipos tentados", mas permite a aplicação da tentativa à grande maioria dos delitos, é preciso utilizar o tipo do crime consumado, unindo-o, como já explicado em nota anterior, à previsão legal da tentativa (art. 14, II, CP), conseguindo-se atingir e punir a parte anterior à consumação.

Observa-se que o legislador se preocupou não somente em punir a prática delituosa quando consumada, mas também a tentativa, ou seja, mesmo que o agente não alcance seu objetivo por circunstancias alheias a sua vontade haverá punição pelos atos não consumados.

A tentativa possui três elementos em sua estrutura, sendo elas: o início da execução do crime, a ausência de consumação por circunstâncias alheias à vontade do agente e o dolo de consumação, sendo esse último igual ao da consumação.

Segundo o Código Penal (BRASIL, 1940) o crime somente não se consuma por circunstâncias alheias à vontade do agente: tinha a intenção de alcançar a consumação, mas por circunstâncias alheias à sua vontade não conseguiu atingir seu objetivo. A decisão do indivíduo é idêntica no crime consumado e no crime tentado. Outro elemento da tentativa é a não consumação do crime por circunstancias alheias à vontade do agente. Apesar da vontade inicial do sujeito em realizar o crime, o iter pode ser interrompido pela sua própria vontade e pela interferência de circunstancias alheias a ela. No primeiro, há desistência voluntaria ou arrependimento eficaz (art. 15), no segundo, existe tentativa punível.

Damásio de Jesus (2014, p.377 e 378) explica,

As circunstâncias estranhas ao elemento subjetivo do agente podem atuar de forma diversa. Podem obstar o autor de prosseguir na realização da conduta atuando "em certo sentido psicofísico, deixando incompleto o fato não somente objetiva, mas também subjetivamente", ou impedem seja completado o tipo por serem absolutamente alheias à sua vontade, não obstante tenha realizado "todo o necessário" para a produção do resultado. Na primeira hipótese, os atos de execução, embora iniciados, ficaram incompletos; na segunda, a fase de execução ocorreu normalmente, mas o resultado não se verificou.

Ainda de acordo com o jurista não é necessário que o iter seja logo interrompido anteriormente a consumação. Basta que a interrupção seja durante a realização dos atos executórios.

\section{DO FURTO PREVILEGIADO}


Trata-se de furto privilegiado a figura prevista no $\S 2$ 20 do artigo 155 do Código Penal (BRASIL, 1940) que diz:

§ 2 o - Se o criminoso é primário, e é de pequeno valor a coisa furtada, o juiz pode substituir a pena de reclusão pela de detenção, diminuí-la de um a dois terços, ou aplicar somente a pena de multa.

O artigo dispõe sobre a possibilidade da substituição da pena de reclusão pela de detenção, a diminuição de um a dois terços, e aplicação somente de multa, caso o réu seja primário, ou seja, não é reincidente e a coisa de pequeno valor. É comum, quando o objeto é de pequeno valor se falar em aplicação do principio da insignificância que é conduta atípica e subsidiariamente se fala em furto privilegiado, pois caso não seja acolhido o princípio da insignificância, seja aplicado a diminuição de pena prevista no § 20 do artigo 155 do código penal (BRASIL, 1940).

Porém, não se pode confundir um com o outro, pois a diferença reside no fato de que na aplicação do princípio da insignificância o agente é absolvido, já na aplicação do § 20 do artigo 155 do código penal (BRASIL, 1940) o agente tem sua pena diminuída.

Possuindo o réu primariedade e com o pequeno valor da coisa, o mesmo terá direito a uma das alternativas previstas no $\S 2$ 을 do artigo 155 do código penal (BRASIL, 1940) devendo o julgador considera-las.

Em relação à questão da possibilidade de aplicação do § 20 do artigo 155 do código penal (BRASIL, 1940) as modalidades qualificadas, a resposta é positiva, pois beneficia o agente, razão pela qual, por questões de politica criminal, faz-se mister a sua aplicação.

\section{DO CABIMENTO DA TENTATIVA NO FURTO PREVILEGIADO}

Em analise as decisões de tribunais superiores o que se tem se entendido majoritariamente é que o agente que tenta praticar o furto privilegiado é absolvido com fundamento no principio da insignificância, pois entendem que a imposição de sanção penal seria desproporcional, entretanto, em todas elas podemos encontrar a afirmação de que houve tentativa de furto privilegiado.

Vejamos a decisão do STJ abaixo:

HABEAS CORPUS. AÇÃO PENAL. TENTATIVA DE FURTO PRIVILEGIADO. RESFURTIVA. VALOR ÍNFIMO. CONDUTA DE MÍNIMA OFENSIVIDADE PARA O DIREITOPENAL. ATIPICIDADE MATERIAL. PRINCÍPIO DA INSIGNIFICÂNCIA. ABSOLVIÇÃO. POSSIBILIDADE. ORDEM CONCEDIDA. 1. Segundo a jurisprudência do Supremo Tribunal Federal, o princípio da insignificância tem como base a mínima ofensividade da conduta do agente, a ausência de periculosidade social da ação, o reduzido grau de reprovabilidade do comportamento e a inexpressividade da lesão jurídica provocada. 2. Hipótese de tentativa de furto privilegiado de duas latas de bombom, não havendo notícia de que a vítima tenha logrado prejuízo algum, seja com a conduta do acusado ou com a consequência dela, tendo em vista que os objetos foram recuperados, mostrando-se desproporcional a imposição de sanção penal no caso, pois o resultado jurídico mostra-se absolutamente irrelevante. 3. Embora a conduta do paciente se amolde à tipicidade formal e subjetiva, ausente, no caso, a tipicidade material, que consiste na relevância penal da ação e do resultado em face da significância da lesão produzida ao bem jurídico tutelado pelo Estado. 4. Ordem concedida para, aplicando-se o princípio da insignificância, absolver o paciente, com fundamento no art. 386,inciso III, do Código de Processo Penal.

(STJ - HC: 204006 SP 2011/0085817-5, Relator: Ministro JORGE MUSSI, Data de Julgamento: 21/06/2011, T5 - QUINTA TURMA, Data de Publicação: DJe 01/08/2011) 
Também o STF tem entendido de modo a aplicar o princípio da insignificância nos delitos de tentativa de furto privilegiado, ou seja, mais uma afirmação de que ocorreu a tentativa de furto privilegiado:

Ementa: PENAL. HABEAS CORPUS. PACIENTE CONDENADO PELA TENTATIVA DE FURTO PRIVILEGIADO. PRINCÍPIO DA INSIGNIFICÂNCIA. ATIPICIDADE DA CONDUTA DO AGENTE. RECONHECIMENTO. ORDEM CONCEDIDA. I - A aplicação do princípio da insignificância, de modo a tornar a ação atípica, exige a satisfação, de forma concomitante, de certos requisitos, quais sejam, conduta minimamente ofensiva, ausência de periculosidade social da ação, reduzido grau de reprovabilidade do comportamento e lesão jurídica inexpressiva. II - In casu, tenho por preenchidos os requisitos necessários ao reconhecimento do crime de bagatela. Isso porque, além da pequena expressividade econômica dos objetos subtraídos (R\$ 181,50), deve-se destacar que o crime não chegou a se consumar, de modo que da conduta do agente não adveio nenhum prejuízo relevante à vítima ou à sociedade. III - Os registros criminais existentes em nome do paciente devem ser examinados cum granus salis e sem perder de vista a garantia constitucional da presunção de não culpabilidade, em conjunto com as demais circunstâncias judiciais que envolveram o delito. IV - Ordem concedida para restabelecer a sentença absolutória.

(STF - HC: 115890 MG, Relator: Min. RICARDO LEWANDOWSKI, Data de Julgamento: 07/05/2013, Segunda Turma, Data de Publicação: DJe-095 DIVULG 20-05-2013 PUBLIC 21-05-2013).

Também TJRS reconheceu a tentativa do furto privilegiado:

APELAÇÃO CRIME. CRIMES CONTRA O PATRIMÔNIO. FURTO QUALIFICADO. CONDENAÇÃO MANTIDA. TENTATIVA RECONHECIDA. PRIVILEGIADORA. EXTINÇÃO DA PUNIBILIDADE.

$[\ldots]$

Furto privilegiado. Tem direito à privilegiadora do art. 155, § 20, do Código Penal, o réu tecnicamente primário, visto que o crime não foi cometido com grave ameaça ou violência contra pessoa, o fato é de pequena repercussão, a coisa é de pequeno valor - equivalente ao salário mínimo vigente à época do fato - e foi restituída à vítima. Prescrição retroativa reconhecida. APELO PARCIALMENTE PROVIDO. EXTINTA A PUNIBILIDADE, DE OFÍCIO.

(Apelação Crime № 70045095742, Quinta Câmara Criminal, Tribunal de Justiça do RS, Relator: Diogenes Vicente Hassan Ribeiro, Julgado em 23/05/2012)

Em ambas as decisões foram aplicadas o princípio da insignificância, porém reconhecida a tentativa do furto privilegiado.

Não obstante, a doutrina não abordar sobre a possibilidade do cabimento da tentativa em furto privilegiado, é possível a análise do tema com base na jurisprudência, e a conclusão de que é possível a tentativa no furto privilegiado.

\section{CONCLUSÃO}

Por fim, ao fazer a analise do tema foi possível entender e concluir pela possibilidade do cabimento da tentativa ao furto privilegiado, pois, ainda que o tema não seja abordado detalhadamente na doutrina, na jurisprudência majoritariamente tem sido possível a tentativa de furto privilegiado, ainda que na maioria dos casos o agente é absolvido com base no principio da insignificância é afirmado que houve a tentativa do furto privilegiado.

Dada à importância do assunto, torna-se necessário uma maior atenção ao julgamento dos delitos de furto de pequeno valor, devendo o julgador atentar sempre ao princípio da proporcionalidade a fim de evitar sanções desnecessárias ou excessivas, pois se trata de delito, e deve ser punido, porém sempre com atenção ao referido princípio. 


\section{REFERÊNCIAS}

BRASIL. Congresso Nacional. Decreto-Lei 2.848, de 7 de Dezembro de 1940. Dispõe sobre o Código Penal. Disponível em: < http://www.planalto.gov.br/ccivil_03/decretolei/Del2848compilado.htm>. Acesso em: 14 ago. 2018.

BRASIL. Congresso Nacional. Lei 10.406, de 10 de Janeiro de 2002.. Dispõe sobre o Código Civil. Disponível em: < http://www.planalto.gov.br/ccivil_03/Leis/2002/l10406.htm>. Acesso em: 14 ago. 2018.

BRASIL. Superior Tribunal de Justiça. Habeas Corpus. Tentativa de furto privilegiado. Habeas Corpus n.o 204006. Impetrante: Fernanda Costa Impetrado: Tribunal de Justiça do Estado de São Paulo. Relator: Ministro Jorge Mussi. 21 de junho de 2011. Disponível em: < https://stj.jusbrasil.com.br/jurisprudencia/21104309/habeas-corpus-hc-204006-sp-20110085817-5-stj/relatorio-e-voto-21104311>. Acesso em: 15 ago. 2018.

BRASIL. Superior Tribunal de Justiça. Habeas Corpus. Paciente condenado pela tentativa de furto privilegiado. Habeas Corpus n. 115890. Impetrante: Anderson Carvalho Silva. Impetrado: Tribunal de Justiça do Estado de Minas Gerais. Relator: Ministro Ricardo Lewandowski. 07 de maio de 2013. Disponível em: < https://stf.jusbrasil.com.br/jurisprudencia/23290551/habeas-corpus-hc-115890-mgstf/inteiro-teor-111671722?ref=juris-tabs>. Acesso em: 15 ago. 2018.

BRASIL. Tribunal de Justiça do Rio Grande do Sul. Apelação Cível. Crimes contra o patrimônio. Furto qualificado. Condenação mantida. Tentativa reconhecida. Apelação cível $\mathrm{n}$. o 70045095742. Impetrante: Anderson Carvalho Silva. Impetrado: Tribunal de Justiça do Estado de Minas Gerais. Relator: Diogenes Vicente. 23 de maio de 2012. Disponível em: < http://blueberrywebsites.com.br/talon/o-furto-privilegiado/>. Acesso em: 15 ago. 2018.

GRECO, Rogério. Curso de Direito Penal. 13.ed.Niterói, RJ: Impetus, 2016. p. 536.

Curso de Direito Penal. 13.ed.Niterói, RJ: Impetus, 2016. p. 556.

Curso de Direito Penal. Vol.2. 18.ed.Niterói, RJ: Impetus, 2016. p. 550.

JESUS, Damásio de. Direito penal, 10 volume: parte geral. 35. ed. - São Paulo : Saraiva, 2013, p.377 e 378. Disponível em: < https://integrada.minhabiblioteca.com.br/\#/books/9788502219670/cfi/377!/4/4@0.00:0.00 >. Acesso em: 29/04/2018.

NUCCl, Guilherme de Souza. Código penal comentado. 17. ed. rev., atual. e ampl. - Rio de Janeiro: $\quad$ Forense, p.172. Disponível em: < 
https://integrada.minhabiblioteca.com.br/\#/books/9788530973865/cfi/6/10!/4/6/2@0:0 > Acesso em: 29/04/2018. 